\title{
Efficacy of midazolam administration to control blood pressure in patients diagnosed with 'Hypertensive crisis': a Randomized Clinical Trial
}

Mohammad Reza Khorsand

Shahrood University of Medical Sciences

Mostafa Enayatrad

Shahrood University of Medical Sciences

Seyed Meysam Yekesadat

Shahrood University of Medical Sciences

Maryam Khodayar

Shahrood University of Medical Sciences

Amir Noyani ( $\nabla$ a.noyani@shmu.ac.ir)

Shahrood University of Medical Sciences https://orcid.org/0000-0002-3614-1150

Original Research

Keywords: Hypertensive crisis, midazolam, captopril, emergency

Posted Date: June 15th, 2020

DOI: https://doi.org/10.21203/rs.3.rs-34962/v1

License: (9) This work is licensed under a Creative Commons Attribution 4.0 International License. Read Full License 


\section{Abstract}

\section{Introduction:}

Hypertensive crisis defines as a sudden rise in blood pressure that can adversely affect the vital organs. As such, it is recommended to take midazolam to lower the blood pressure in patients of hypertensive crisis. This study aims to investigate the midazolam efficacy as an emergency care to control the blood pressure in patients diagnosed with hypertensive crisis.

\section{Methods}

The current paper represents a double-blinded clinical trial study that examines the patients of the hypertensive crisis who referred to Imam Hossein Hospital of Shahroud, 2018. Patients with systolic/diastolic blood pressure greater than 180/110 mm Hg and with healthy vital organs were selected randomly and divided into three groups of 43 participants. All patients' blood pressure in both arms, and after a period of 10 minutes in the left arm, was checked and was checked again after administering the medication for 4 times of 15 minutes till 1 hour complete. IBM SPSS Amos 23 was implemented. One-way ANOVA, Chi-Square and Repeated measure tests were performed to carry out statistical analysis. The level of significance of 0.05 was considered.

\section{Results}

in the group of midazolam, it was observed a reduction of $20.6 \%(P=0.024), 17.4 \%(P=0.001)$, and $19.1 \%(P=0.009)$ for the systolic blood pressure, diastolic blood pressure, and blood pressure average, respectively. In such case, it was also indicated to be a significant difference of the reduction before and after the treatment. The group of captopril showed a decrease of $19.9 \%(P=0.001), 13.5 \%(P=0.008)$, and $16.7 \%(P=0.001)$ for the systolic blood pressure, diastolic blood pressure, and blood pressure average, respectively. It was also observed to be a significant difference in reducing the blood pressure before and after the treatment. The group of midazolam and captopril showed the greatest reduction of blood pressure before, in the middle, and after carrying out the treatment methods. As such, systolic blood pressure, diastolic blood pressure, and the blood pressure average changed to the reduction of $23.5 \%(P=0.047), 17.4 \%(P=0.021)$, and $20.5 \%(P=0.031)$, respectively. No significant difference was observed among these three groups $(P=0.239)$.

\section{Introduction}

Hypertension can mainly risk cardiovascular and non-communicable diseases. Some factors including life expectancy, health care improvement, and appropriate treatment serves to increase hypertension prevalence $(1,2)$. In developed countries, nearly 20 to 30 percent of adults are suffering from hypertension (3) Some previous studies reported a 10 to 17 percent incidence of hypertension for the 
eastern Mediterranean and middle east countries (4). Nowadays, hypertension and cardiovascular diseases are increasing in Iranian people. Results of studies in 2006 revealed that the hypertension prevalence is $23.13 \%$ in Iranian population aged $25-64$ years $(5,6)$. World health organization estimates that 1 in 8 cause of death is due to hypertension. It is also known as the third biggest risk factor for death (7).

Hypertension may also pose a major problem by emerging 'hypertensive crisis' in its patients. Only 1 percent of patients potentially meet a hypertensive crisis (8). In patients with hypertensive crisis, this problem acts to suddenly rises blood pressure that may or may not injure vital organs such as heart, kidney, brain, and eyes. Patients' blood pressure should be lowered within minutes to hours under that condition. Therefore, appropriate treatment serves crucially as a controller of blood pressure $(9,10)$. Any immediate and appropriate lack of dealing over hypertension crisis results in early death due to kidney failures (11).

Patients of hypertensive crisis are administered either with oral or sublingual medications. Till 1996, it was instructed to administer nifedipine as emergency care for patients of high blood pressure (12-15). Later, studies revealed and recommended to use the captopril (16) over nifedipine due to the harmful and deadly effects of nifedipine including sudden fall in blood pressure, brain and heart ischemia, and sudden death. Besides, other studies proved the beneficial affects this medication show $(17,18)$. Both nifedipine $10 \mathrm{mg}$ and captopril $25 \mathrm{mg}$ indicated to lower blood pressure almost similarly according to the studies. As a sublingual tablet, however, captopril showed no serious side effects. It should be noted that nifedipine can lower the pressure of blood more immediate than captopril, which this can also make this medication to its fatal side effects $(19,20)$. However, nifedipine and captopril can only display the blood pressure control, means that their efficacy strongly depends on their half-life. Therefore, it highlights the importance of those medications that can prevent hypertension reoccurrence by controlling the underlying mechanism such as stress in patients. They can also ensure the effectiveness by affecting the psychological systems. In this definition, sedative and antianxiety medications such as benzodiazepine can help considerably $(21,22)$. Midazolam, a new benzodiazepine, can decrease the pressure of blood by taking the anxiety as well as stress into control. Midazolam can also help patients with immediate actions. However, a few studies have investigated the clinical effectiveness in midazolam on blood pressure (23). Some side effects such as airway obstruction are expected if the medication is exceeded the stated doze (24). Midazolam is maintaining its popularity as emergency care for the fast action, short elimination time of half-life, minor side effects, and the low cost (25). However, a comparative study of intervention methods is required to provide evidence in case of the effectiveness of midazolam. This paper, thus, compares the efficacy of controlling blood pressure in both midazolam and captopril administration in patients diagnosed with hypertensive crisis.

\section{Methods}

\section{Study design}


The present study is a double-blind randomized clinical trial (RCT) performed on patients with hypertensive crisis presenting to Imam Hossein, Shahroud, Iran, from December 2018 to May 2019, to evaluate the efficacy of midazolam in control the blood pressure in patients diagnosed with hypertensive crisis. The study protocol was approved by ethics committee of Shahroud University of Medical Sciences under the number IR.SHMU.REC.1397.076 and registered on Iranian registry of clinical trials under the number IRCTID IRCT20181010041299N1. Researchers adhered to the principles of Helsinki ethical recommendations and confidentiality of patients' information throughout the study period.

\section{Study population}

All adult patients with hypertensive crisis were enrolled in our study. The sampling was convenient and we used random allocation software. We enrolled 129 patients based on our inclusion criteria; Patients with a systolic and/or diastolic blood pressure greater than $180 / 110 \mathrm{~mm} \mathrm{Hg}$, aged between 18-80 years were included in this study and asked to sign the informed consent by stating their agreement. Patients with the left-sided chronic heart failure, chronic renal failure, cardiovascular diseases, history of brain and heart stroke, usage of benzodiazepines during the last week, usage of muscle relaxation medications such as baclofen or antianxiety medications such as zolpidem or buspirone, allergy to captopril/midazolam, pregnancy and infant, an acute hypertension condition in which doctor prefers rather midazolam and captopril, and patients with a difference of $15 \mathrm{~mm} \mathrm{Hg}$ for blood pressure indicated by each arm were excluded.

Based on Yilmaz et al study (26), for each group after the calculation of systolic blood pressure deviation and mean score in the patients who were administered by captopril and midazolam, and the significant level of 0.05 and the power size of $80 \%$, the total sample size reached the number of 129 by considering $10 \%$ loss of our samples. Thus, each group of treatment added 43 more participants to investigate.

\section{Intervention}

Comparison was performed for the two main drugs, captopril orally $(25 \mathrm{mg})$ (Exir Pharma Co, Tehran, Iran) and midazolam intramuscularly (1 mg) (Exir Pharma Co, Tehran, Iran). This research, on the other hand, employed two placebos including vitamin B and distilled water instead of captopril and midazolam, respectively, for patients to receive.

Using randomization software, individuals were divided into three treatment groups. Patients who agreed with the informed consent were randomly chosen to participate in one of the groups of treatment. In Control group (captopril tablets and injected placebo distilled water), Intervention group 1 (midazolam injection and placebo vitamin B tablets) and Intervention group 2 (midazolam injection and Captopril) was prescribed. For blinding patients and analyzing the type of drug used in each individual, a placebo was used, and each medical group was assigned a code that only an emergency specialist could interpret.

\section{Procedure}


Data of the patients' information were collected based on a questionnaire the represents two sections. The first section asks for demographic information such as age, location, and sex. The second one represents patients with the required information on the procedure of treatment including systolic/diastolic blood pressure, pulse and breath rate, side effects, etc.

All patients' blood pressure in both arms, and after a period of 10 minutes in the left arm, was checked by the nurse doing the shift work. Blood pressure in patients was also checked while laying them on the bed and on the standard basis, using a mercury manometer. If a patient was reported to have a greater systolic and diastolic blood pressure greater than $180 / 110 \mathrm{~mm} \mathrm{Hg}$ after the period of 10 minutes or more, the patient must be transferred to one of the groups of treatment after revising exclusion and inclusion criteria by the medicine specialist. The patients in each group of treatment were given medications in accordance with the treatment protocols stated. On the standard basis, all Patients blood pressure were checked for 4 times of 15 minutes after administrating treatment methods to compare them in details. If patients experience any side effects after giving them any specific medication and in the middle of checking the blood pressure, the patient should visit the medicine specialist for the required treatment and stop attending the study. In the case of lack of success to lower patients' blood pressure after checking the blood pressure for the last time, it was instructed to employ other treatment methods to control the pressure of blood in the patient and to avoid giving the medications investigated in this study.

\section{Outcome}

This study mainly focused on the outcome of blood pressure in patients. The secondary outcome that was investigated was about the side effects cause of the treatment methods. To calculate the mean arterial pressure, the systolic and diastolic blood pressure was calculated by the sum of systolic pressures and two times of diastolic pressure divided by the number of three. The nurse specialist checked the patients for the interval of 15 minutes to give the required medications to patients in the case of developing some side effects in them, including drowsiness and shortness of breath.

\section{Statistical Analysis}

Data were analyzed using SPSS software version 16 and with intention to treat analysis method. Oneway ANOVA, Chi-Square and Repeated measure tests were used for comparisons. Normality of the data was measured by the KS test. In this study, $p=0.05$ was considered as significance level. Findings were presented as mean \pm standard deviation or frequency and percentage.

\section{Results}

This study investigates 129 patients including 45 males (34.9\%) and 84 females (65.1\%). The number of $106(82.2 \%)$ patients' lives in the city and 23 patients (17.8\%) live in the village. The average age of the participants is $61.76 \pm 11.44$ year. As Table 1 shows, no significant difference is observed among the groups of treatment in terms of sex type $(P=0.398)$, location $(P=0.809)$, age $(P=0.634)$, history of diseases $(P=0.858)$, and history of blood pressure $(P=0.956)$ (Table 1$)$. 
Table 1

Patients Characteristics in the treatment groups.

\begin{tabular}{|c|c|c|c|c|c|}
\hline \multirow[t]{2}{*}{ Variable } & & $\begin{array}{l}\text { Midazolam } \\
\text { group }\end{array}$ & $\begin{array}{l}\text { Captopril } \\
\text { groun }\end{array}$ & $\begin{array}{l}\text { Midazolam and } \\
\text { Captopril aroun }\end{array}$ & \multirow{2}{*}{$\begin{array}{l}\text { Level of } \\
\text { Significant }\end{array}$} \\
\hline & & $\begin{array}{l}\text { Number } \\
\text { (percent) }\end{array}$ & $\begin{array}{l}\text { Number } \\
\text { (percent) }\end{array}$ & $\begin{array}{l}\text { Number } \\
\text { (percent) }\end{array}$ & \\
\hline \multirow[t]{2}{*}{ Sex } & Male & $18(41.9)$ & 15 (34.9) & $12(27.9)$ & \multirow[t]{2}{*}{0.398} \\
\hline & Female & $25(58.1)$ & $28(65.1)$ & $31(72.1)$ & \\
\hline \multirow[t]{2}{*}{ Location } & City & 36 (83.7) & $34(79.1)$ & 36 (83.7) & \multirow[t]{2}{*}{0.809} \\
\hline & Village & $7(16.3)$ & $9(20.9)$ & $7(16.3)$ & \\
\hline \multirow[t]{2}{*}{ Age } & Man & $62.9 \pm 9.9$ & $62.1 \pm 11$ & $55.5 \pm 19.1$ & \multirow[t]{2}{*}{0.634} \\
\hline & Woman & $61.2 \pm 10.9$ & $63.2 \pm 8.7$ & $62.4 \pm 11.2$ & \\
\hline \multirow{2}{*}{$\begin{array}{l}\text { History of } \\
\text { Disease }\end{array}$} & Yes & 36 (83.7) & 38 (81.4) & 34 (79.1) & \multirow[t]{2}{*}{0.858} \\
\hline & No & 7 (16.3) & 8 (18.6) & 9 (20.9) & \\
\hline \multirow{2}{*}{$\begin{array}{l}\text { History of blood } \\
\text { pressure }\end{array}$} & Yes & 33 (76.7) & 33 (76.7) & $34(79.1)$ & \multirow[t]{2}{*}{0.956} \\
\hline & No & $10(23.3)$ & $10(23.3)$ & $9(20.9)$ & \\
\hline
\end{tabular}

Checking blood pressure in patients as the first time in different specific timings, Table 2 indicates systolic, diastolic, and the mean of blood pressure as $195.1 \pm 15.5,107.3 \pm 11.5$, and $136.5 \pm 10.2 \mathrm{~mm} \mathrm{Hg}$, respectively. After the period of 10 minutes, the numbers changed to $191.7 \pm 13.7,104.7 \pm 9.6$, and 133.7 $\pm 7.4 \mathrm{~mm} \mathrm{Hg}$ by checking the blood pressure for the second time with no intervention. The numbers decreased to $151.9 \pm 24.5,86.2 \pm 10.9$, and $108.1 \pm 14.2$ after the intervening as to administer the medications and checking the blood pressure in an interval of 15 minutes till 1 hour complete. The significant difference is observed among systolic $(P=0.024)$, diastolic $(P=0.001)$, and the mean of blood pressure $(P=0.009)$ comparing before and after the treatment. The participants of captopril group report $199.6 \pm 17.4,107 \pm 12.6$, and $137.9 \pm 11.7$ for systolic and diastolic mean of blood pressure and the mean of blood pressure, respectively, for the first time attending the study. After the period of 10 minutes the numbers changes to $193.6 \pm 15.5,103.9 \pm 10.2$, and $133.8 \pm 10$, with no intervention. The numbers decreased to $111.2 \pm 11.9,89.4 \pm 8.9$, and $155 \pm 20.6$ after the intervening as to administer the medications and checking the blood pressure in an interval of 15 minutes till 1 hour complete. The significant difference is observed among systolic $(P=0.001)$, diastolic $(P=0.008)$, and the mean of blood pressure $(P=0.009)$ comparing before and after the treatment. The participants of captopril and midazolam groups report $198.6 \pm 12.9,106.4 \pm 11.3$, and $137.1 \pm 9.3$ for systolic and diastolic mean of blood pressure and the mean of blood pressure, respectively, for the first time attending the study. After the period of 10 minutes the numbers changes to $195.7 \pm 13,104.7 \pm 9.1$, and $135 \pm 8.3$, with no intervention. The numbers decreased to $149.4 \pm 23,86 \pm 9.1$, and $107.1 \pm 11.4$ after the intervening as to 
administer the medications and checking the blood pressure in an interval of 15 minutes till 1 hour complete. The significant difference is observed among systolic $(P=0.047)$, diastolic $(P=0.021)$, and the mean of blood pressure $(P=0.031)$ comparing before and after the treatment.

Table 2

Blood pressure average at different times in the treatment groups

\begin{tabular}{|c|c|c|c|c|c|c|c|c|}
\hline \multicolumn{2}{|c|}{ Time of Measurement } & \multirow{2}{*}{$\begin{array}{l}0 \\
195.1 \\
\pm 15.5\end{array}$} & \multirow{2}{*}{$\begin{array}{l}10 \\
191.7 \\
\pm 13.7\end{array}$} & \multirow{2}{*}{$\begin{array}{l}15 \\
191.7 \\
\pm 19.5\end{array}$} & \multirow{2}{*}{$\begin{array}{l}30 \\
161.7 \\
\pm 21\end{array}$} & \multirow{2}{*}{$\begin{array}{l}45 \\
155.3 \\
\pm 22.4\end{array}$} & \multirow{2}{*}{$\begin{array}{l}60 \\
151.9 \\
\pm 24.5\end{array}$} & \multirow{2}{*}{$\begin{array}{l}\text { Level of } \\
\text { Significant } \\
0.024\end{array}$} \\
\hline Midazolam Group & Systolic & & & & & & & \\
\hline & Diastolic & $\begin{array}{l}107.3 \\
\pm 11.5\end{array}$ & $\begin{array}{l}104.7 \\
\pm 9.6\end{array}$ & $\begin{array}{l}94.3 \\
\pm 10.3\end{array}$ & $\begin{array}{l}89.5 \\
\pm 10.8\end{array}$ & $\begin{array}{l}86.9 \\
\pm 9.8\end{array}$ & $\begin{array}{l}86.2 \\
\pm 10.9\end{array}$ & 0.001 \\
\hline & Average & $\begin{array}{l}136.5 \\
\pm 10.2\end{array}$ & $\begin{array}{l}133.7 \\
\pm 7.4\end{array}$ & $\begin{array}{l}118.4 \\
\pm 11.5\end{array}$ & $\begin{array}{l}113.6 \\
\pm 12.4\end{array}$ & $\begin{array}{l}109.7 \\
\pm 12.5\end{array}$ & $\begin{array}{l}108.1 \\
\pm 14.2\end{array}$ & 0.009 \\
\hline \multirow[t]{3}{*}{ Captopril group } & Systolic & $\begin{array}{l}199.6 \\
\pm 17.4\end{array}$ & $\begin{array}{l}193.6 \\
\pm 15.5\end{array}$ & $\begin{array}{l}170.8 \\
\pm 20.2\end{array}$ & $\begin{array}{l}163 \pm \\
17.7\end{array}$ & $\begin{array}{l}158.7 \\
\pm 17\end{array}$ & $\begin{array}{l}155 \pm \\
20.6\end{array}$ & 0.001 \\
\hline & Diastolic & $\begin{array}{l}107 \pm \\
12.6\end{array}$ & $\begin{array}{l}103.9 \\
\pm 10.2\end{array}$ & $\begin{array}{l}97 \pm \\
11.6\end{array}$ & $\begin{array}{l}93.8 \\
\pm 10.1\end{array}$ & $\begin{array}{l}91.4 \\
\pm 10.6\end{array}$ & $\begin{array}{l}89.4 \\
\pm 8.9\end{array}$ & 0.008 \\
\hline & Average & $\begin{array}{l}137.9 \\
\pm 11.7\end{array}$ & $\begin{array}{l}133.8 \\
\pm 10\end{array}$ & $\begin{array}{l}121.6 \\
\pm 12.9\end{array}$ & $\begin{array}{l}116.8 \\
\pm 11.2\end{array}$ & $\begin{array}{l}113.8 \\
\pm 12\end{array}$ & $\begin{array}{l}111.2 \\
\pm 11.9\end{array}$ & 0.001 \\
\hline \multirow[t]{3}{*}{$\begin{array}{l}\text { Midazolam and } \\
\text { Captopril group }\end{array}$} & Systolic & $\begin{array}{l}198.6 \\
\pm 12.9\end{array}$ & $\begin{array}{l}195.7 \\
\pm 13\end{array}$ & $\begin{array}{l}163.7 \\
\pm 23.2\end{array}$ & $\begin{array}{l}158.4 \\
\pm 23.4\end{array}$ & $\begin{array}{l}152.7 \\
\pm 22.6\end{array}$ & $\begin{array}{l}149.4 \\
\pm 23\end{array}$ & 0.047 \\
\hline & Diastolic & $\begin{array}{l}106.4 \\
\pm 11.3\end{array}$ & $\begin{array}{l}104.7 \\
\pm 9.1\end{array}$ & $\begin{array}{l}93 \pm \\
11.7\end{array}$ & $\begin{array}{l}90.1 \\
\pm 11.1\end{array}$ & $\begin{array}{l}87.4 \\
\pm 9.6\end{array}$ & $\begin{array}{l}86 \pm \\
9.1\end{array}$ & 0.021 \\
\hline & Average & $\begin{array}{l}137.1 \\
\pm 9.3\end{array}$ & $\begin{array}{l}135 \pm \\
8.3\end{array}$ & $\begin{array}{l}116.5 \\
\pm 14.5\end{array}$ & $\begin{array}{l}112.9 \\
\pm 13.4\end{array}$ & $\begin{array}{l}109.2 \\
\pm 11.8\end{array}$ & $\begin{array}{l}107.1 \\
\pm 11.4\end{array}$ & 0.031 \\
\hline
\end{tabular}

As it can be seen in Table 3, the average of systolic blood pressures was decreased to 20.6, 19.9, and 23.5 for the groups of midazolam, captopril, and midazolam and captopril group, respectively. The analysis results indicate that there is no significant difference among all three groups in terms of lowering the blood pressure $(P=0.239)$, although the greatest reduction of intragroup has targeted the group of both midazolam and captopril administration. Besides, the diastolic blood pressure drops in the groups of midazolam, captopril, and midazolam and captopril indicating the percentages of 17.4, 13.5 and 17.4, respectively. Despite the highest reduction in the group of captopril, there is no significant difference among the groups of treatment $(P=0.083)$ in terms of diastolic blood pressure decrease. With respect to the average pressure of blood in all three groups, it is observed that the midazolam, captopril, and midazolam and captopril groups show the average blood pressure reduction of $19.1 \%, 16.7 \%$, and $20.5 \%$. Note that this reduction obtains no significant difference in all three groups $(P=0.123)$. 
Table 3

Blood pressure reduction Percentage among treatment groups

\begin{tabular}{|c|c|c|c|c|c|c|c|c|}
\hline \multicolumn{2}{|c|}{ Time of Measurement } & \multirow{2}{*}{$\begin{array}{l}0 \\
1.6 \\
\pm \\
2.9\end{array}$} & \multirow{2}{*}{$\begin{array}{l}10 \\
12.8 \\
\pm 8.8\end{array}$} & \multirow{2}{*}{$\begin{array}{l}15 \\
2.9 \pm \\
7\end{array}$} & \multirow{2}{*}{$\begin{array}{l}30 \\
\\
3.8 \\
\pm \\
7.1\end{array}$} & \multirow{2}{*}{$\begin{array}{l}45 \\
2.1 \\
\pm \\
6.9\end{array}$} & \multirow{2}{*}{$\begin{array}{l}60 \\
20.6 \\
\pm 12\end{array}$} & \multirow{2}{*}{$\begin{array}{l}\text { Level of } \\
\text { Significant }\end{array}$} \\
\hline $\begin{array}{l}\text { systolic blood } \\
\text { pressure }\end{array}$ & Midazolam & & & & & & & \\
\hline & Captopril & $\begin{array}{l}2.8 \\
\pm \\
4.3\end{array}$ & $\begin{array}{l}11.8 \\
\pm 7.2\end{array}$ & $\begin{array}{l}4.2 \pm \\
6.4\end{array}$ & $\begin{array}{l}2.5 \\
\pm \\
4.8\end{array}$ & $\begin{array}{l}2.4 \\
\pm \\
2.5\end{array}$ & $\begin{array}{r}19.9 \\
\pm 7.5\end{array}$ & \\
\hline & $\begin{array}{l}\text { Midazolam and } \\
\text { Captopril }\end{array}$ & $\begin{array}{l}1.4 \\
\pm \\
2.8\end{array}$ & $\begin{array}{l}16.2 \\
\pm 11\end{array}$ & $\begin{array}{l}2.6 \pm \\
9.6\end{array}$ & $\begin{array}{l}3.2 \\
\pm 7\end{array}$ & $\begin{array}{l}1.2 \\
\pm \\
5.5\end{array}$ & $\begin{array}{l}23.5 \\
\pm 10.9\end{array}$ & \\
\hline \multirow[t]{3}{*}{$\begin{array}{l}\text { Diastolic blood } \\
\text { pressure }\end{array}$} & Midazolam & $\begin{array}{l}2 \pm \\
5.4\end{array}$ & $\begin{array}{l}9.8 \pm \\
7.6\end{array}$ & $\begin{array}{l}4.7 \pm \\
9.2\end{array}$ & $\begin{array}{l}2.5 \\
\pm \\
5.9\end{array}$ & $\begin{array}{l}0.7 \\
\pm \\
6.4\end{array}$ & $\begin{array}{l}17.4 \\
\pm 9.5\end{array}$ & 0.083 \\
\hline & Captopril & $\begin{array}{l}2.5 \\
\pm \\
5.3\end{array}$ & $\begin{array}{l}6.3 \pm \\
9.2\end{array}$ & $\begin{array}{l}2.9 \pm \\
7.7\end{array}$ & $\begin{array}{l}2.6 \\
\pm \\
3.8\end{array}$ & $\begin{array}{l}1.8 \\
\pm \\
4.9\end{array}$ & $\begin{array}{l}13.5 \\
\pm 8.9\end{array}$ & \\
\hline & $\begin{array}{l}\text { Midazolam and } \\
\text { Captopril }\end{array}$ & $\begin{array}{l}1.1 \\
\pm \\
5.9\end{array}$ & $\begin{array}{l}11.2 \\
\pm 8.6\end{array}$ & $\begin{array}{l}2.4 \pm \\
10.8\end{array}$ & $\begin{array}{l}2.5 \\
\pm \\
6.9\end{array}$ & $\begin{array}{l}1.4 \\
\pm \\
5.3\end{array}$ & $\begin{array}{l}17.4 \\
\pm 9.3\end{array}$ & \\
\hline \multirow[t]{3}{*}{$\begin{array}{l}\text { Normal blood } \\
\text { pressure }\end{array}$} & Midazolam & $\begin{array}{l}1.8 \\
\pm 4\end{array}$ & $\begin{array}{l}11.3 \\
\pm 7.2\end{array}$ & $\begin{array}{l}3.9 \pm \\
7.2\end{array}$ & $\begin{array}{l}3.2 \\
\pm \\
5.6\end{array}$ & $\begin{array}{l}1.4 \\
\pm \\
5.9\end{array}$ & $\begin{array}{r}19.1 \\
\pm 9.8\end{array}$ & 0.123 \\
\hline & Captopril & $\begin{array}{l}2.7 \\
\pm \\
4.6\end{array}$ & $9 \pm 7$ & $\begin{array}{l}3.6 \pm \\
6.4\end{array}$ & $\begin{array}{l}2.6 \\
\pm \\
3.5\end{array}$ & $\begin{array}{l}1.2 \\
\pm \\
4.5\end{array}$ & $\begin{array}{l}16.7 \\
\pm 7\end{array}$ & \\
\hline & $\begin{array}{l}\text { Midazolam and } \\
\text { Captopril }\end{array}$ & $\begin{array}{l}1.3 \\
\pm \\
4.2\end{array}$ & $\begin{array}{l}13.7 \\
\pm 9\end{array}$ & $\begin{array}{l}2.5 \pm \\
9.3\end{array}$ & $\begin{array}{l}2.9 \\
\pm \\
5.9\end{array}$ & $\begin{array}{l}1.7 \\
\pm \\
4.6\end{array}$ & $\begin{array}{l}20.5 \\
\pm 8.2\end{array}$ & \\
\hline
\end{tabular}

As Fig. 1 suggests, blood pressure is reduced in all three groups over time. Although the blood pressure in the midazolam and captopril group (Intervention group 2) is shown to be highest, but, as time passes, this group also shows the highest decrease of blood pressure comparing the other two groups. The midazolam group (Intervention group 1) outperforms the captopril group (Control group) in terms of the highest reduction of systolic blood pressure. Despite that fact that the blood pressure in the midazolam and captopril group is shown to be highest, but, as time passes, this group also shows the highest decrease of diastolic blood pressure comparing the other two groups. Figure 2 also indicates that the midazolam group outperforms the group of captopril in terms of lowering the pressure of blood in patients. 
In terms of side effects in each of the treatment groups, people were examined at different times of the study. A total of 7 patients (5.4\%) of the total subjects underwent complications from the drug. Of these, 3 were in the midazolam and placebo groups, 1 was in the captopril and placebo groups, and 3 were in the midazolam and captopril groups. The results showed that there was no significant difference between the three treatment groups in terms of the side effects of drug use $(P=0.547)$.

\section{Discussion}

Hypertension can cause serious problems including Hypertension Crisis. Since controlling hypertensive pressure suggest not to lower the blood pressure greater than $30 \%$ of its primary level, performing an appropriate treatment is, thus, crucially effective in controlling blood pressure (27) .

In this study, the highest blood pressure reduction in the first measurement (15 minutes after prescription) was observed after the medication administration in all three treatment groups and gradually met the maximum reduction. As such, the blood pressure decreased deliberately and no brain nor cardiac side effects were observed in the patients. There was no significant difference in systolic, diastolic and normal blood pressure in all three treatment groups.

But in all three measurements, midazolam and captopril groups showed the greatest reduction in blood pressure, which can be due to the simultaneous effect of the two medications on blood pressure in the patients. There was no significant difference between Midazolam group and captopril group in terms of systolic blood pressure reduction. While in diastolic blood pressure and the average blood pressure the midazolam group decreased greater than the captopril group. Although this difference was not statistically significant, it could indicate that Midazolam peak effect is greater in reducing blood pressure. In this study, the groups were similar in terms of age, sex, hypertension history and other diseases and also high blood pressure medication history, as no significant difference were observed.

All three groups of this investigation showed the highest blood pressure reduction within 15 minutes after performing the treatment. While in many studies, the most reduction of pressure in patients with hypertensive crisis occurred 30 minutes after medications $(17,18,28)$. This can be due to different levels of measuring in different studies that were not equal. Some investigations on captopril showed the peak effect timings of a $25-\mathrm{mg}$ sublingual dose. It was shown to be 30 minutes after administration and continued for at least two hours $(17,18,28)$.

In the study by Castillo, $12.35 \mathrm{mg}$ captopril resulted to a decrease of $66 \%$ of the diastolic blood pressure in patients with critical hypertension within 30 minutes as the diastolic pressure reached below $100 \mathrm{mmHg}(28)$. In a survey conducted in Turkey, $90 \%$ of people with diastolic blood pressure greater than $120 \mathrm{mmHg}$ reported to have a reduction of blood pressure using $25 \mathrm{mg}$ sublingual captopril with the action time of 60 minutes (29). In the Kazerney study, more than $65 \%$ of the patients with diastolic blood pressure observed a decrease within 30 minutes after administrating captopril (30). 
The present study showed greater blood pressure reduction in the midazolam group comparing to the captopril group. Although observing the effect of this drug on decreasing diastolic blood pressure and the average blood pressure showed no significant difference between treatment groups, these results can be indicative of the efficacy of midazolam in reducing the pressure in the patients of hypertensive crisis. This can also be due to the effects midazolam aims at physiological and biological stresses that can lead to a greater reduction in blood pressure. In a study by Jones et al. (31) that was performed on animals, midazolam reported to be able to decrease the pressure about $10-20 \%$ on arterial blood pressure after performing the injection.

A study by Forester et al. (32) on several volunteers showed a medium decrease in arterial blood pressure by midazolam. In a study by Heikkilä et al. (33), a rapid decline in systolic blood pressure between $24 \%$ and $32 \%$ and diastolic blood pressure was observed between $29 \%$ and $33 \%$.

\section{Limitations}

One limitation of our study was that the sample size might be insufficient to detect the exact drug effects. Further clinical trials with larger sample sizes and longer follow-up should therefore be performed to identify its role. Another limitation of this study is the lack of measurement of stress and anxiety in patients with hypertensive crisis. Regarding the effect of stress and anxiety on hypertension, and considering that midazolam as an effective drug in reducing stress, it is recommended to measure stress and anxiety in these patients using standard instruments.

\section{Conclusion}

Midazolam is a suitable drug, safe, effective, affordable and accessible with low side effects that can be useful for controlling hypertensive. Considering the fact that it is a sedative drug, it is also beneficial in the rapid reduction of blood pressure associated with stress and has several therapeutic effects.

\section{Declarations}

\section{Conflict Of Interest}

None declared.

\section{Funding}

This study was conducted with a support from Clinical Research Development Unit of Imam Hossein Hospital of Shahroud(found number:414).

\section{Authors' Contribution}


All the authors met the standards of authorship based on the recommendations of the International Committee of Medical Journal Editors.

\section{Acknowledgments}

We gratefully thank the emergency department personnel of Imam Hossein Hospital of Shahroud, and the Clinical Research Development Unit of Imam Hossein Hospital for providing the funding help for the project(found number:414).

\section{References}

1. Azizi F, Ghanbarian A, Madjid M, Rahmani M. Distribution of blood pressure and prevalence of hypertension in Tehran adult population: Tehran Lipid and Glucose Study (TLGS), 1999-2000. J Hum Hypertens. 2002;16(5):305.

2. Gu D, Reynolds K, Wu X, Chen J, Duan X, Muntner P, et al. Prevalence, awareness, treatment, and control of hypertension in china. Hypertension. 2002;40(6):920-7.

3. Fox CS, Evans JC, Larson MG, Kannel WB, Levy D. Temporal trends in coronary heart disease mortality and sudden cardiac death from 1950 to 1999: the Framingham Heart Study. Circulation. 2004;110(5):522-7.

4. Chaman R, Yunesian M, Hajimohamadi A, Taramsari MG. Investigating hypertension prevalence and some of its influential factors in an ethnically variant rural sample. Knowledge Health. 2008;3:39-42.

5. Ebrahimi M, Mansournia MA, Haghdoost AA, Abazari A, Alaeddini F, Mirzazadeh A, et al. Social disparities in prevalence, treatment and control of hypertension in Iran: second National Surveillance of Risk Factors of Noncommunicable Diseases, 2006. J Hypertens. 2010;28(8):1620-9.

6. Maleki M, Noohi F, Oraii S, Mohammad K, Eftekharzadeh M, Mirhaji P, et al. Prevalence of cardiovascular risk factors in Tehran: Healthy Heart Project. Iranian Heart J. 1998;1(Suppl 1):130.

7. Ahmadi A, Mobasheri M, Soori H. Prevalence of major coronary heart disease risk factors in Iran. International Journal of Epidemiologic Research. 2014;1(1).

8. Calhoun DA, Oparil S. Treatment of hypertensive crisis. N Engl J Med. 1990;323(17):1177-83.

9. Rag Wogifford J. Management of hypertensive crisis. JAMA. 1991;266:829-35.

10. Grysiewicz RA, Ruland SD. Hypertensive encephalopathy and acute blood pressure management after hemorrhagic stroke. Hypertension: Springer; 2011. pp. 127-41.

11. Hansson L, Hedner T, Dahlof B. Prospective randomized open blinded end-point (PROBE) study. A novel design for intervention trials. Prospective Randomized Open Blinded End-Point. Blood Press. 1992;1(2):113-9.

12. Gifford RW. Jr. Management of hypertensive crises. JAMA. 1991;266(6):829-35.

13. Abraham G, Shukkur A, Van Der Meulen J, Johny KV. Sublingual nifedipine-a safe and simple therapy for hypertensive emergencies. Br J Clin Pract. 1986;40(11):478-81. 
14. Houston MC. Treatment of hypertensive urgencies and emergencies with nifedipine. Am Heart J. 1986;111(5):963-9.

15. Fanning GL. Nifedipine for hypertensive emergencies. JAMA. 1997;277(10):789-90. author reply 90 $-1$.

16. Grossman E, Nadler M, Sharabi Y, Thaler M, Shachar A, Shamiss A. Antianxiety treatment in patients with excessive hypertension. Am J Hypertens. 2005;18(9 Pt 1):1174-7.

17. Tschollar W, Belz GG. Sublingual captopril in hypertensive crisis. Lancet. 1985;2(8445):34-5.

18. Hauger-Klevene JH. Captopril in hypertensive crisis. Lancet. 1985;2(8457):732-3.

19. Angeli P, Chiesa M, Caregaro L, Merkel C, Sacerdoti D, Rondana M, et al. Comparison of sublingual captopril and nifedipine in immediate treatment of hypertensive emergencies. A randomized, singleblind clinical trial. Arch Intern Med. 1991;151(4):678-82.

20. Gemici K, Karakoc Y, Ersoy A, Baran II, Gullulu S, Cordan J. A Comparison of Safety and Efficacy of Sublingual Captopril with Sublingual Nifedipine in Hypertensive Crisis. Int J Angiol. 1999;8(3):147-9.

21. Kitajima T, Kanbayashi T, Saito Y, Takahashi Y, Ogawa Y, Sugiyama T, et al. Diazepam reduces both arterial blood pressure and muscle sympathetic nerve activity in human. Neurosci Lett. 2004;355(12):77-80.

22. Kostić M, Krunić N, Nikolić L, Nikolić V, Najman S, Kocić J. Određivanje količine rezidualnog monomera u pojedinim akrilatima za bazu proteze i mogućnosti njegove redukcije. Vojnosanitarni Pregled. 2009;66:223-7.

23. Bauer KP, Dom PM, Ramirez AM, O'Flaherty JE. Preoperative intravenous midazolam: benefits beyond anxiolysis. J Clin Anesth. 2004;16(3):177-83.

24. Persson MP, Nilsson A, Hartvig P. Relation of sedation and amnesia to plasma concentrations of midazolam in surgical patients. Clin Pharmacol Ther. 1988;43(3):324-31.

25. Kain ZN, Mayes LC, Bell C, Weisman S, Hofstadter MB, Rimar S. Premedication in the United States: a status report. Anesth Analg. 1997;84(2):427-32.

26. Yilmaz S, Pekdemir M, Tural U, Uygun M. Comparison of alprazolam versus captopril in high blood pressure: a randomized controlled trial. Blood Press. 2011;20(4):239-43.

27. McGraw Hill

Harrison's principles of internal medicine Braunwald E, Fauci AS, Kasper DL, Hauser SL, Longo DL, Jameson JL. Harrison's principles of internal medicine: McGraw Hill; 2001.

28. Castillo AC, Rodriguez M, Gonzalez E, Rodriguez F, Estruch J. Dose-response effect of sublingual captopril in hypertensive crises. The Journal of Clinical Pharmacology. 1988;28(7):667-70.

29. Komsuoglu B, Sengun B, Bayram A, Komsuoglu SS. Treatment of hypertensive urgencies with oral nifedipine, nicardipine, and captopril. Angiology. 1991;42(6):447-54.

30. Kazerani H, Hajimoradi B. Evaluation of the effect of captopril subacute in the treatment of critical hypertension. Journal of Hamadan University of Medical Sciences Health Services. 2006;4(43):5-10. 
31. Jones DJ, Stehling LC, Zauder HL. Cardiovascular responses to diazepam and midazolam maleate in the dog. Anesthesiology. 1979;51(5):430-4.

32. Forster A, Juge 0 , Morel D. Effects of midazolam on cerebral blood flow in human volunteers. Anesthesiology. 1982;56(6):453-5.

33. Heikkilä H, Jalonen J, Arola M, Kanto J, Laaksonen V. Midazolam as adjunct to high-dose fentanyl anaesthesia for coronary artery bypass grafting operation. Acta anaesthesiologica scandinavica. 1984;28(6):683-9.

\section{Figures}

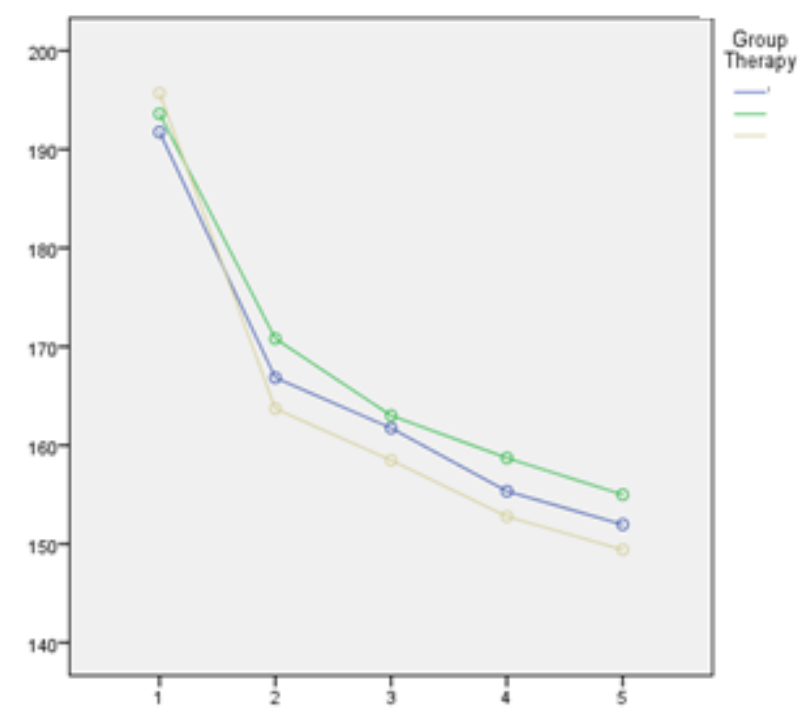

Figure 1

The decreasing process of systolic blood pressure at different times. 


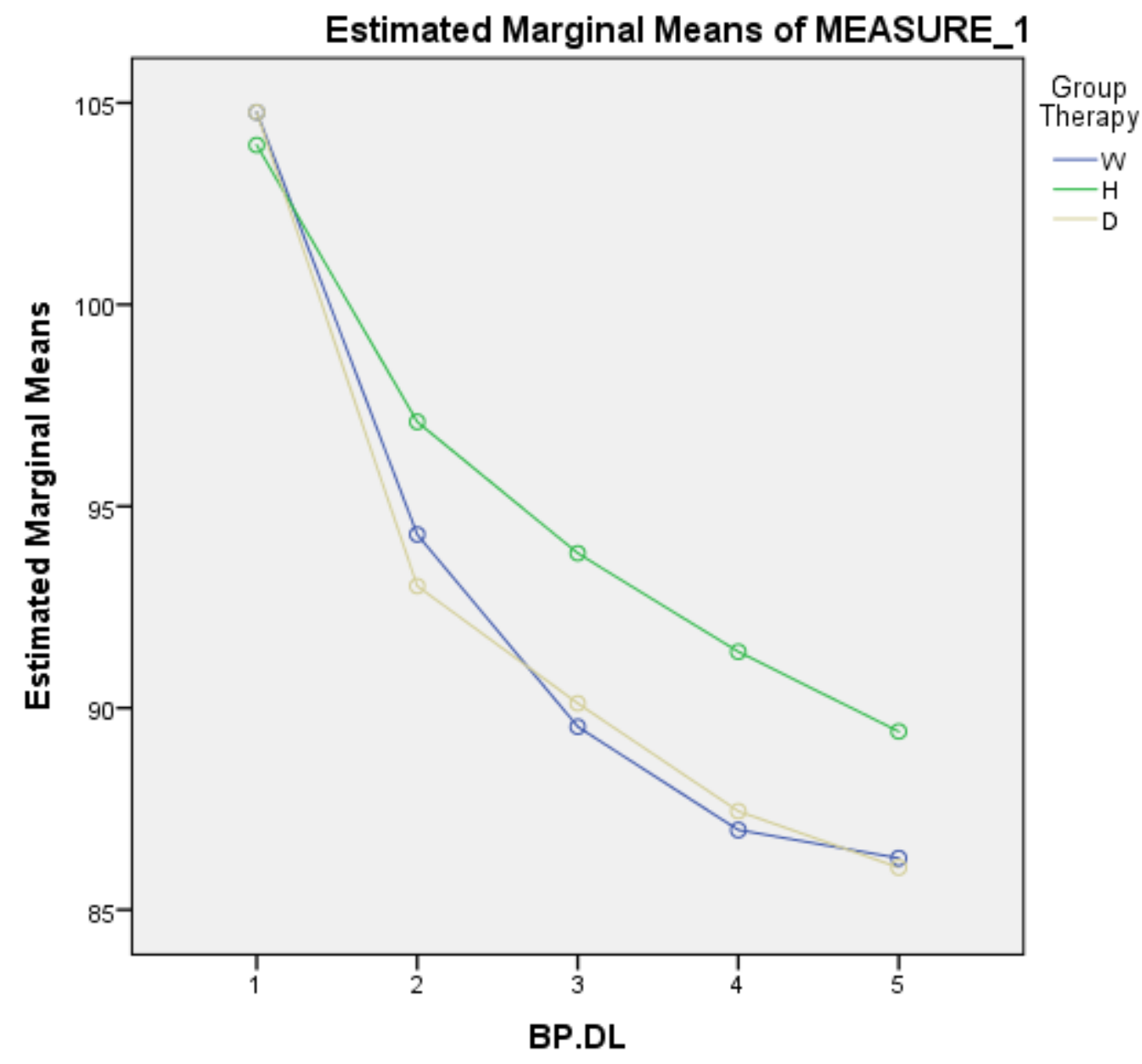

Figure 2

The decreasing process of diastolic blood pressure at different times. 